\title{
Anorexia and its Metaphors
}

\author{
Susannah Wilson* \\ Department of French Studies, University of Warwick \\ *Correspondence: S.M.Wilson@warwick.ac.uk
}

Peer review: This article has been subject to a double blind peer review process

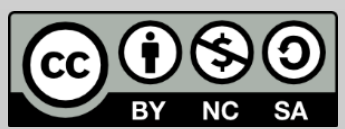

(C) Copyright: The Authors. This article is issued under the terms of the Creative Commons Attribution NonCommercial Share Alike License, which permits use and redistribution of the work provided that the original author and source are credited, the work is not used for commercial purposes and that any derivative works are made available under the same license terms.

\begin{abstract}
This article highlights questions about a number of popularly held beliefs regarding anorexia nervosa. The beliefs this article addresses include that it is a 'disease' caused by socio-cultural pressures on women to be excessively thin or self-effacing; and that in the post-war period the problem has increased to the level of an epidemic. Using the influential insights offered by cultural critic Susan Sontag's consideration of 'illness as metaphor', the article examines the ways in which these beliefs are culturally constructed through metaphorical thinking. Without discounting the socio-cultural explanations for the increased diagnosis of anorexia, it suggests that the breaking down of these powerful metaphors would be constructive in order to achieve a more measured cultural view of the problem. Drawing on key publications from the last 50 years, contemporary press reports and historical research on anorexia I argue that the myths surrounding the disorder confer on it a potency that is out of proportion to its cultural importance.
\end{abstract}

Keywords: anorexia, metaphor, eating disorders, body image, female body, visibility

There is a set of core beliefs about anorexia nervosa that are popularly held, but which are coming under constant scrutiny. These beliefs are commonly expressed in metaphorical terms. The first is that anorexia, like alcoholism and drug addiction, is a 'disease', although psychiatry classifies it as a disorder. The second is that it is a socio-cultural problem of the affluent Western nations in the post-war period, a metaphorical acting out of the unreasonable expectations women are supposed to satisfy. The third is that we are witnessing an 'epidemic' of this 'disease' among young women in Western societies (Makino et al., 2004; Pike et al., 2015). ${ }^{i}$ I use these terms tentatively not to cast aspersions, but in order to introduce the problem of discussing a concrete behaviour and its consequences in the metaphorical language of illness. This article is a consideration of the controversy surrounding competing explanations of anorexia, through an exploration of the metaphors used to talk about it. It also considers other possible ways of thinking about anorexia, a 
different set of metaphors, which offer possible ways of reconciling these views.

So widespread and unchallenged is the orthodoxy, in lay culture at least, I often wonder why do I not see more obviously anorexic students in the course of my work as a lecturer in UK higher education." After all, the university contains plenty of exemplars of the classic anorexic stereotype: young - aged, say, 18 or 21 - and typically female, privileged, intelligent, high achieving and uneasy in her skin. Yet, it is my impression that the number of women who present with serious eating disorders is vanishingly small, if you will forgive the expression. Disordered eating of one kind or another may of course be much more common, and indeed less visible. When thinking notionally about the small number of cases I have dealt with in a pastoral role, I have found myself wholly convinced by the eloquent - often impassioned, poetic - cultural explanations for the disorder, at least in theory. In day-to-day life, however, I am increasingly uncertain about the neat line of reasoning that anorexia is symbolic of a cultural crisis, or a passive-aggressive rebellion by girls against a set of confusing and impossible expectations placed upon them by the patriarchy or by mothers complicit in it. The disorder remains uncommon, and, if our culture has produced anorexia, then my instinct is that we should see more of it.

The cultural critic Susan Sontag, in her influential study IIIness as Metaphor suggests that metaphorical thinking about illness distorts reality, and is a barrier to truth. She describes how metaphors of illness may be 'punitive or sentimental fantasies', arguing instead 'that illness is not a metaphor, and that the most truthful way of regarding illness-and the healthiest way of being ill-is one most purified of, most resistant to, metaphoric thinking' (Sontag, 1978: 2-3). Sontag also says that the diseases most likely to be treated in this metaphorical way are those which threaten, because they are not understood: 'The fantasies inspired by TB in the last century, by cancer now, are responses to a disease thought to be intractable and capricious - that is, a disease not understood-in an era in which medicine's central premise is that all diseases can be cured' (Sontag, 1978: 5). Anorexia nervosa is a phenomenon that we have struggled to understand, and which has therefore attracted metaphorical explanations. Each new research finding brings us closer to a much hoped-for cure. If it can be cured, it can be understood and its power defused.

Excessive and self-punishing behaviour in the pursuit of discipline, virtue and physical perfection is relatively common in both men and women: who cannot visualise the lycra-clad middle-aged man and his obsession with road cycling? Or the gym-addicted celebrity mother feverishly 
dieting and spinning her way back into her tight, pre-pregnancy, girl-sized body? There are people who, perhaps unadvisedly, adhere to 'calorierestriction', fruitarian or strict vegan regimes in the hope of achieving long life and freedom from common western lifestyle ailments (Haycock, 2008). Since these activities do not usually threaten lives or inflict direct harm, and their less extreme manifestations may even be positive, we tolerate them, we 'live and let live'. And so we should, for human behaviour is nothing if not inexplicable and extreme. Anorexia, perhaps, sits at the very end point of these ascetic behaviours to which we are all more or less drawn.

The most extreme eating disorders can be fatal, with anorexia being the deadliest. The Diagnostic and Statistical Manual of Mental Disorders has historically reported an impressively high mortality rate for anorexia compared to other mental disorders. ${ }^{\mathrm{iii}}$ It is around ten times more likely to be diagnosed in women than in men, and the cultural metaphors invoked to explain the disorder relate exclusively to the female experience(www.rcpsych.ac.uk/mentalhealthinfoforall/problems/eatingd isorders/eatingdisorders.aspx). For this reason, I do not discuss male anorexia here. The impact of this disorder on those affected, and on their families and friends, can be catastrophic. In my choice of focus, and in raising questions about these core beliefs, it is not my intention to minimise the distress and misery wreaked by anorexia - in men or women. It is, rather, to offer a reflection on how we think about behaviours and choices metaphorically as diseases.

Anorexia nervosa is, in epidemiological terms, still rare; an illustrative figure provided by the Royal College of Psychiatrists claims it affects no more than one fifteen-year-old female in every 150 , and one male in 1000 (ibid.). By way of comparison, anorexia affects many less than autism, but many more than cystic fibrosis or multiple sclerosis. Compared to the impact of the most common cancers in middle age, its effect is small. Yet the popular press exhibits a peculiar fascination with this visible problem. For example, former Prada model and recovered anorectic, Georgina Wilkin, believes, along with many others, that 'eating disorders have become normalised' (Wilkin, 2013). Yet is it commonplace to be hospitalised for anorexia? The statistics cited above suggest it is not. In relation to the specific micro-culture of the fashion industry, the comment is probably more pertinent. The idea that anorexia has reached the level of an epidemic, that it is widespread and even contagious, is expressed through this idea of normalisation. But is this a distortion? If most of our young women maintain a healthy weight, why do we feel so threatened by this disorder in particular? What, if anything, does anorexia mean today? 
Anorexia nervosa was first identified as an illness in the 1870s, simultaneously in England and France by the Victorian physician Sir William Gull and the French psychiatrist Charles Lasègue. At this time, it was not interpreted metaphorically as a cultural malaise but in rather concrete, moral terms. For Gull, it was a 'habit' that needed to be 'corrected', and he believed the patient's view should be disregarded (Gull, 1874: 22-28; Lasègue, 1873). At this time, in both England and France re-feeding was emphasised and enforced weight gain seen as successful treatment. Freud had little to say about anorexia, but he was one of the first to begin drawing metaphorical parallels-between appetite, drives and libido. This would lead to a more complex, psychoanalytically informed interpretation of the disorder: why would a woman starve herself ? $^{\text {iv }}$ With psychoanalysis, the understanding of the disorder moved from the realm of the visual to the verbal: from an emphasis on a physical transformation (from emaciation to fleshiness) to a focus on the psychological meaning of a behaviour that went against natural instinct (Wilson, 2014; Brumberg, 2000).

With this shift in emphasis came a range of metaphorical interpretations of the meaning of anorexia for those in its grip. In the course of my research on the history of anorexia, I have grown familiar with and sympathetic to the feminist cultural argument that anorexia represents, according to psychoanalyst Susie Orbach, a 'metaphor for our age'. Orbach sees anorexia as extreme acquiescence to the expectation in patriarchal society that a woman be passive, self-effacing and compliant (Orbach, 2005: xv). Yet paradoxically, anorexia also represents a rebellion against those expectations, a 'hunger strike'. Orbach's polemical account, based on years of experience with eating-disordered women at the Women's Therapy Centre in London, suggests that many medical interventions are ineffective because they are based on coercion and the suppression of the anorectic's beliefs, rather than on a concerted attempt to listen to her. Orbach does not believe that there is a gene for anorexia; neither does she 'blame' families. She views anorectics as doing, in a perverse way, exactly what the mass media and society require of them.

Some of the key metaphors used to describe and interpret anorexic behaviour centre on the ideas of paradox, epidemic, power, visibility and polarity. And like with cancer, we often speak of anorexia in militaristic terms: we refer to a girl's 'battle' with anorexia, and celebrate her 'beating' or 'overcoming' the disease. If a woman dies, as did fashion models Isabelle Caro in 2010 and Ana Carolina Reston in 2006, we speak of her 'losing her battle' with the disorder. We rail against the idea of a 'size zero', a symbol of metaphorical annihilation. 
Many commentators over the years have offered eloquent analyses of the paradoxes that lie at the centre of the anorexic mind-set, if such a thing exists. Marilyn Lawrence has outlined the 'control paradox', whereby anorectics exercise absolute control over their bodies (and indeed their families and carers) but feel they are reeling out of control (Lawrence, 1979). The pioneering post-war adolescent psychiatrist and psychoanalyst Hilde Bruch was the first clinician to present the view that the disease was a cultural problem, through her insistence that its symptoms were meaningful rather than baffling and perverse (Bruch, 2001). Its meaning was rooted in complex unconscious conflicts within the young woman, in response to an impossible set of double binds presented by family and society. Mothers and daughters were psychologically enmeshed; girls whose burgeoning femininity did not sit right with them unconsciously wanted to become the sons their fathers lacked. Anorexia was, in part, an attempt to arrest development, to squeeze back into a more certain if restricted role. Whether she realised it or not, the anorectic sought to deny adult sexuality and to become an androgynous and unsexed non-adult.

Since these theories came to prominence, between about the 1960s and the 1990s, the view of anorexia as culturally determined has dominated popular and journalistic discourse. In the media, anorexia is presented in terms of metaphors or similes of natural crisis and infection: anorexia levels 'soar' and, we are assured, it is definitely a disease: 'it's like cancer or the flu' (Dugan, 2014). Most newspaper discussions today amount to crude correlations drawn between the statistical rise in anorexia and the mass media insistence on the aesthetic of thinness in women. The latest manifestation of the cultural-environmental explanation for anorexia is the moral panic blaming social media for activating the illness in young women. In these contexts, the key metaphors again relate to combat: one invoked time and again is the 'trigger'. Something external sets off a sequence of events that spiral destructively down. People are being 'bombarded by these images of what seems to be the ideal body' (Boseley, 2014). More subtle metaphors used to explain anorexia as a cultural phenomenon include novelist Rachel Cusk's concept of the 'anorexic statement'. Cusk reflects the orthodoxy when she asks, 'when a woman starves herself, what is she saying?' Like Orbach, Cusk speaks in terms of subversion and disruption: 'the anorexic statement [...] asks questions not just of mothers or fathers or fashion editors, but of the whole societal basis for the female image' (Cusk, 2012).

Despite these widely held beliefs about the causes of anorexia, advances in neuroscience have suggested a possible genetic predisposition to eating disorders. Crucially, these suggest that starvation alters brain chemistry in ways that may cause ('trigger') anorexic behaviour. In other 
words, if your body is starved you are likely to start exhibiting the typical behavioural rituals of an anorectic. This challenge to the purely cultural interpretation is only beginning to gain ground, and is still a long way from being embraced in the popular view. Interestingly, discussions of these new explanations for an old problem are just as likely to have recourse to metaphor. Science writer Carrie Arnold argues from the impassioned perspective of a recovered anorectic, believing that the problem is essentially biological. Drawing heavily on mechanical metaphors, she suggests that women like her are 'pre-wired for anorexia from birth'. She argues this is what makes it so easy to slip into illness, and so difficult to recover. Arnold says that food phobia, and the terror of re-gaining weight, are far more powerful forces than 'supermodels or a diet-obsessed culture'. Arnold also talks in terms of triggers and switches, to suggest the opposite of the previous examples: that 'something far deeper than culture [is] at work' (Arnold, 2013: 5-8). This seemingly inconsequential statement reveals the bias of her approach: she sees an inherent hierarchy in which science is hard truth, untainted by culture, and culture is all the superficial stuff that sits on the surface of our lives. For scholars in the arts and humanities, the suggestion that culture is not 'deep', is inconsequential or without real meaning, is quite simply unacceptable, as is the idea that phobias and terrors can be neatly disentangled from cultural context (Orbach, 2005; Bruch, 2001).

Yet for scientists, to minimise the importance of observable neurochemical alterations in the brain in order to sustain a purely cultural understanding of anorexia is equally distorted. For cultural commentators - which include psychoanalysts (for psychoanalysis is, first and foremost, a method for analysing the effects of that 'deep' culture) diseases mental or otherwise cannot be solely explained in terms of physical pathology. Diseases always have a broader cultural and metaphorical existence. They always mean more than what is happening physically inside a human body. Yet for science, it is naïve to impose a neatly cultural and metaphorical explanation of a disease without balancing it against biological evidence.

According to Arnold, new approaches to treatment are once again emphasising the importance of feeding and weight gain as they did in the nineteenth century, albeit with a more reasonable approach to issues such as forced feeding. This is in order to short-circuit the damaging process occurring inside the anorectic's brain that compels her behaviour. The DSM 5 sits on the fence, noting 'A range of brain abnormalities has been described in anorexia nervosa [...] The degree to which these findings reflect changes associated with malnutrition versus primary abnormalities associated with the disorder is unclear' (DSM 5: 342). Arnold suggests that the way to cure anorexia is to stop the 
starvation. Only when the girl stops starving can the brain's chemistry be righted, and patterns of abnormal thinking alleviated. So here, the pendulum has swung back to where it started. Perhaps it will be possible, as Sontag showed with TB, to de-mythologise a disease if we can pin down its cause. Were the early observations of anorectics intuitively correct, even without knowledge of neurochemistry? Arnold's findings suggest that they were.

Perhaps it would be useful to stop talking of an 'epidemic' and to start considering what constitutes metaphorical immunity to the disorder. Despite the appeal of the biological explanation to anorectics - you do not have to blame your parents, and it makes drug treatments possible the jury is still out on whether the chicken of starvation or the egg of altered neurochemistry came first. One criticism frequently levelled against orthodox Western medicine is its disproportionate focus on disease as opposed to health. Compared to non-Western models such as the Chinese yin-yang symbol of balance and complementarity, our conception of disease is heavily based on dichotomous thinking: the familiar oppositions of darkness and light, disease and health, pain and comfort. As we view death and life as opposing rather than transitional or even complementary states, we find disease and 'disorder' difficult to accept. We want to fight it, to destroy it. We want to win. We know much less about why people are healthy.

So, instead of 'what causes anorexia?' a better question might be: 'how do people avoid it?' Whatever the core belief, we know more about what may cause and perpetuate anorexia than about why most women do not have it. The mass media and broader cultural conspiracy to provoke disordered eating in women could not be more robust. So might this be further evidence of the biological theory of the disorder, that it is only triggered in susceptible women? The comparative rareness of the disorder suggests there may be as-yet unknown reasons why some women develop anorexia. It reassures me to look around my lecture theatre and, despite the pressure upon them to consider their bodies with disgust and loathing, to see a room packed with women who look as women have always looked: lean or big; curved thighs and full busts alongside slender and athletic shapes. Resolutely 'human shaped', as Caitlin Moran exhorts us to be in How to be a Woman (Moran, 2011: 111).

Alongside the beliefs in cultural or biological causation, there is a third possibility. This is the controversial idea of choice. A similar metaphor used in the discussion of other self-destructive behaviours is 'addiction'. One popular view is that addiction is a 'disease' that you either 'have' or are free from. According to this belief, popularised by Alcoholics 
Anonymous, you are still an addict even when your body is clean of drugs or alcohol. Yet, addiction does not exist in any concrete way: it is not pathology in the cells of the body. You cannot do a blood test and 'find' a substance or abnormality called addiction. You may find drugs or alcohol, or the signs and symptoms of a body in withdrawal (the result of physical dependency), but not 'addiction'. Addiction, like anorexia, is a metaphor we use to describe the fraught process of being psychologically and physically dependent on something that makes us feel temporarily good, unsustainably so. It is the same paradox of complete ritual control over the apparatus and behaviour required to attain the good feeling, combined with lack of control: the inability to sustain the fleeting endorphin high or to prevent the come down.

If we consider anorexia in terms of addiction, then the increased presence of visual images in everyday life since the 1870 s may explain how it begins. Non-suicidal self-injury (NSSI), more usually called 'selfharm' or simply 'cutting', is sometimes interpreted as an addiction not because those who engage in it are masochistic or suicidal but because cutting, like anorexia, is a temporary solution to pain. Cutting takes away pain. Heroin takes away pain. Starvation takes away pain. Or, at least, it takes the person doing it away from her pain. In discussions of self-injury, the importance of 'trigger images' has been demonstrated (Lader, et al. 2007: 1135-1143). A susceptible person will see someone else 'cut', in a film or music video, and this stimulates him or her to emulate the behaviour. If they achieve the neurochemical changes needed to produce a 'high', as a result of the release of endogenous opiates, then they may become compelled to repeat the behaviour, or perhaps 'addicted' ${ }^{v}$ 'If mass-media images of excessively thin women function in the same way as trigger images for anorexia then we may have some means of reconciling the biological and the cultural explanations of the disorder.

With addiction, recent controversies have centred on the shift away from addictions as diseases with victims towards the view that they are choices for which addicts must take responsibility. This view is outlined by the iconoclastic critic of the 'therapeutic state' Jeffrey Schaler (2000), and is promoted in more reactionary terms by UK tabloid journalists such as Peter Hitchens (2012), who is often to be seen on television head-tohead in futile argument with self-confessed celebrity addicts. The line of reasoning is simple, and is incredibly difficult to argue against. Addiction is a choice, and the proof is that it stops when the addict chooses to stop - taking drugs; gambling; starving herself. People do these things because it gives them an immediate sense of feeling good or 'in control', and they stop when they realise it is a shortcut to long-term misery. Most importantly for this discussion, according to Schaler calling behaviour 'addiction' and calling addiction a 'disease' does not help the addict to 
stop. It disempowers and encourages the passivity that prevents recovery. So-called 'addicts' need to know they are in control of what they do, and that they can stop. Only the anorectic choosing to eat, regularly, can stop the natural run of the disorder.

Might we view anorexia, then like addiction, not in metaphorical terms as a disease but in philosophical terms as a choice? Would this possibility liberate or demonise sufferers? Would it help them to understand why others have chosen differently? Might it make them feel empowered when they feel powerless? The relatively simple idea of choice certainly offers a possible explanation for recovery. Yet, one of the strengths of Arnold's book is to demonstrate in clear English the complexity - in biological terms - of something as apparently simple as choosing to eat or not. But psychoanalysis, and to some extent psychiatry, has already undermined the principles of free will and self-control that are at the philosophical centre of western culture's view of the human subject. Even if choice is a difficult idea to deal with, if we can remove the power and aura that surrounds anorexia nervosa by breaking down metaphorical thinking surrounding it, then it may leave people better empowered to take control of their lives. The 'disease' becomes far less meaningful, and possibly less potent. I am not convinced that anorexia is a bigger problem today than the myriad, nebulous wasting diseases that afflicted women in the nineteenth century. The metaphors we have attached to this behaviour have made it more powerful and significant than it needs to be, and the terrifying spectre we have created has elevated it to the status of a cultural symbol. The danger is that it then becomes the embodiment of a chic to which young women aspire. The fashion industry's promotion of an impossible aesthetic ideal does need to be more robustly challenged, but we must also be wary of conferring upon this disorder a grandiosity that is out of proportion to its everyday cultural significance.

\footnotetext{
'Anorexia is a classically Western disease, and it is almost never observed in countries where hunger is a true physical threat. There is evidence that anorexia is on the rise in non-Western contexts, although it is unclear yet from the literature whether this means the disease is culturally bound, and therefore linked to the process of westernisation, or a culturally reactive response to industrialisation.

ii I use the adjective 'anorexic' and the noun 'anorectic' in this article.

iii DSM 5 (2013) records 'The crude mortality rate (CMR) for anorexia nervosa is approximately 5\% per decade.' (342). The DSM IV (2000) recorded a long-term mortality rate of $10-20 \%$ for those hospitalised with anorexia. (1101).

iv Freud described anorexia as 'a melancholia where sexuality is undeveloped' in 'Extracts from the Fleiss Papers' (Freud 2001 [1895]: 200).

"While the interpretation is mine, the information on the release of endogenous opiates is from Nock, 2009: 298.
} 


\section{References}

American Psychiatric Association (2013), Diagnostic and Statistical Manual of Mental Disorders: DSM 5, Washington D.C.: American Psychiatric Publishing

American Psychiatric Association (2000), Diagnostic and Statistical Manual of Mental Disorders: DSM-IV-TR, Washington D.C.: American Psychiatric Association

Arnold, C. (2013), Decoding Anorexia: How Breakthroughs in Science Offer Hope for Eating Disorders, New York/London: Routledge

Boseley, S. (2014), 'Rise in hospital admissions for young people with eating disorders', Guardian, 30 January, http://www.theguardian.com/society/2014/jan/30/rise-hospitaladmissions-young-people-eating-disorders, accessed 6 November 2015

Bruch, H. (2001), The Golden Cage: The Enigma of Anorexia Nervosa, Cambridge, Mass/London: Harvard University Press

Brumberg, J. (2000), Fasting Girls: The History of Anorexia Nervosa, New York: Vintage.

Cusk, R. (2012). 'The anorexic statement', New Statesman, 31 October, http://www.newstatesman.com/lifestyle/lifestyle/2012/10/anorexicstatement, accessed 6 November 2015

Dugan E. (2014), 'Eating disorders soar among teens - and social media is to blame', Independent, 26 January, http://www.independent.co.uk/lifestyle/health-and-families/health-news/exclusive-eating-disorders-soaramong-teens-and-social-media-is-to-blame-9085500.html, accessed 6 November 2015

Freud, S. (2001 [1895]), 'Extracts from the Fleiss Papers', in Standard Edition of the Complete Psychological Works of Sigmund Freud, Vol 1, London: Vintage

Gull, W. (1874), 'Anorexia Nervosa', Transactions of the Clinical Society of London VII: 22-28

Haycock, D. (2008), Mortal Coil: A Short History of Living Longer, New Haven/London: Yale University Press

Hitchens, P. (2012), The War We Never Fought: The British Establishment's Surrender to Drugs, London: Bloomsbury Lader, W. Contario, K. and Whitlock, J. (2007), 'The Internet and SelfInjury: What Psychotherapists Need to Know', Journal of Clinical Psychology, 63: 1135-43 
Lasègue, C. (1873), 'De L'anorexie hystérique', Archives générales de la médecine, 6: 385-403.

Lawrence, M. (1979), 'Anorexia Nervosa: The Control Paradox', Women's Studies International Quarterly, 2: 93-101

Makino, M. K. Tsuboi and L. Dennerstein. (2004). 'Prevalence of Eating Disorders: A Comparison of Western and Non-Western Countries', Medscape General Medicine, 6 (3): 49

Moran, C. (2011), How to Be a Woman, London: Ebury

Nock, M. (2009), Understanding Nonsuicidal Self-Injury: Origins, Assessment, and Treatment, Washington, D.C.: American Psychological Association

Orbach, S. (2005), Hunger Strike: The Anorectic's Struggle as a Metaphor for Our Age, London: Karnac Books

Pike, K. and P. Dunne. (2015). 'The rise of eating disorders in Asia: a review', Journal of Eating Disorders, 48 (6): 1-14

Schaler, J. (2000), Addiction Is a Choice, Chicago: Open Court Sontag, S. (1978), Illness as Metaphor, Harmondsworth: Penguin Wilkin, G. (2013), 'What young girls can learn from my anorexia', Telegraph, 20 September, http://www.telegraph.co.uk/women/womenslife/10323519/Former-model-What-young-girls-can-learn-from-myanorexia.html, accessed 31 March 2016

Wilson, S. (2014), 'The Iconography of Anorexia Nervosa in the Long Nineteenth Century', in Scarth, K. Chung, J. and Scott, F. (eds), Picturing Women's Health, London: Pickering and Chatto: 77-104

To cite this article:

Wilson, S. (2016). Anorexia and its Metaphors. Exchanges: The Warwick Research Journal, 3(2), 216-226. Retrieved from:

http://exchanges.warwick.ac.uk/index.php/exchanges/article/view/84 